\title{
Cardiovascular Risk in Patients with COPD: Cardiovascular Comorbidities in Patients with COPD Increase CAT and mMRC Dyspnea Scores
}

\author{
Jagoda Stojkovic $^{1^{*}(\mathbb{D})}$, Emilija Antova ${ }^{2}$ (D) Dragana Stojkovikj ${ }^{1}$ \\ ${ }^{1}$ University Clinic of Pulmonology and Allergology, Medical Faculty, Ss. Cyril and Methodius University, Skopje, Macedonia; \\ ${ }^{2}$ University Clinic of Cardiology, Medical Faculty, Ss. Cyril and Methodius University, Skopje, Macedonia
}

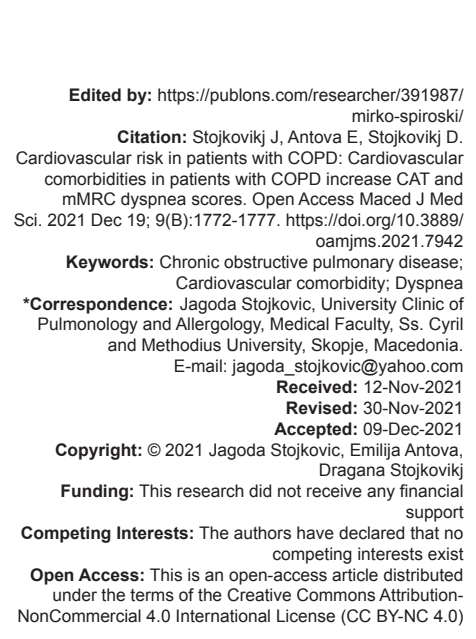

\section{Introduction}

Chronic obstructive pulmonary disease (COPD) is a chronic inflammatory pulmonary disease that causes airflow obstruction of the lungs. Symptoms include breathing difficulty, chronic cough, mucus (sputum) production, and wheezing. COPD is typically caused by long-term exposure to irritating gases or particulate matter, most often from cigarette smoke [1]. People with COPD are at increased risk of developing various numbers of other diseases, first of all: Heart disease (HD), lung cancer, malnutrition, anxiety, depression, osteoporosis, muscle atrophy, metabolic syndrome, diabetes, sleep disturbance, and anemia. All of these diseases potentiate the morbidity of COPD, leading to increased hospitalizations and health-care costs. They can frequently cause death, independently of respiratory failure. Comorbidities make the management of COPD more complex, need to be diagnosed, and treated adequately [1], [2].

In COPD patients, the risk of cardiovascular diseases (CVD) is on average 2-3 times higher than in persons of comparable age in the general population, even when taking into account the risk of smoking [3].

Although the lungs are considered to be the main target organ for smoking, it is well known that other systems are also affected by this risk factor, particularly the cardiovascular system. In addition, decreased pulmonary function is closely associated with an increased risk of congestive heart failure (CHF), myocardial infarction (MI), and atrial fibrillation (AF). Other common risk factors for COPD and CVD are age and healthy lifestyle violation (physical activity witch is impaired in COPD and nutrition) [4]. 
Increased levels of inflammatory markers, such as C-reactive protein and various chemokines, play a significant role in the development of atherosclerosis, coronary heart disease (CHD), $\mathrm{CHF}$, and AF. The content of the same inflammatory markers is increased in many patients with COPD. Moreover, the frequency of exacerbations in COPD is associated with a more pronounced inflammation and increased risk of MI. However, the development of any chronic disease is a complex process, dependent on many factors, and is difficult to explain by one unique mechanism. In addition, there is insufficient evidence today that suppressing inflammation can prevent COPD in combination or without association with other diseases [1], [5], [6].

Individuals susceptible to damage caused by smoking and pollutants can suffer from both heart and lung disease. Just as pulmonary disease can contribute to $\mathrm{HD}$, cardiac illness can itself contribute to pulmonary disease [4].

A number of studies has shown that an increase in the severity of COPD and the appearance of emphysema are associated with a decrease in the size of the heart during X-ray examination. The increase in the size of the lungs due to hyperinflation has a compression effect on the heart muscle, creating unfavorable conditions for its activity, and hindering the implementation of its pumping function. COPD patients with a ratio of inspiratory capacity/total lung capacity (TLC) $<0.25$ were characterized by an impaired left ventricle (LV) function which was closely correlated with a decrease in exercise tolerance during the cardiorespiratory exercise test and a decrease in oxygen pulse indices, confirming the cardiac mechanism of exercise limitation [4]. Later, it was shown that the main reason for the decrease in exercise tolerance was an impairment of the LV diastolic filling. The close correlation of COPD severity according to the Global initiative for chronic Obstructive Lung Disease (GOLD) classification and the basic dimension of the heart chambers have also been demonstrated: Areas of the right and left atria, right ventricle diameter, and left ventricular end-diastolic diameter [2], [5].

Dyspnea refers to the sensation of breathlessness, shortness of breath, or difficulty breathing that are commonly observed in patients with respiratory and cardiac disease. Dyspnea is a common symptom affecting as many as $25 \%$ of patients seen in the ambulatory setting. It can arise from many different underlying conditions and is sometimes a manifestation of a life-threatening disease. Dyspnea is the medical term for shortness of breath, sometimes described as "air hunger." Shortness of breath can range from mild and temporary to serious and long-lasting [6]. Dyspnea is believed to result from disruption of the normal relationship between inspiratory neural drive to breathe and the dynamic response of the respiratory system. Dyspnea is the cardinal symptom in patients with COPD and its severity and magnitude increases as the disease progresses, leading to significant disability (decrease effort tolerance). It manifests initially during exertion and then, as the disease progresses, also during rest. It is caused by airflow obstruction which is secondary to airways inflammation, airways remodeling, and sputum hypersecretion; reduced lung elastic recoil due to emphysema and the obstruction of small airways results in incomplete air expelling ("air trapping"), hyperinflation, and especially dynamic hyperinflation [7], [8] Overall exertional dyspnea in COPD is the result of complex pathophysiological mechanisms including dynamic hyperinflation, increased ventilator demand relative to impaired capacity, hypoxemia, hypercapnia, and neuromechanically dissociation. Dyspnea is the subjective experience, unpleasant feeling, and of discomfort with breathing. For patients with advanced COPD, dyspnea profoundly affects quality of life, so the extent that patients become socially isolated. Dyspnea is associated increased anxiety and depression, decreased health-related quality of life, and reduced survival. Dyspnea intensity appears to play a key role in this cycle in that the greater the severity of dyspnea experienced with inactivity, the more impact on quality of life. Refractory dyspnea is a common and difficult symptom to treat in patients with advanced COPD [9], [10], [11].

\section{Measuring dyspnea}

Various subjective clinical and psychophysical scales and questionnaires are typically used to measure or predict dyspnea.

At present, there exists a large number of scales to classify and characterize dyspnea: The most frequently used in everyday clinical practice are the clinical scales (e.g., MRC or baseline dyspnea index-transition dyspnea index), in which information is obtained directly from the patients through interview) and psychophysical scales (such as the Borg scale or visual analog scale [VAS]), which assess symptom intensity in response to a specific stimulus, for example, exercise) [10].

\section{Aim}

The aim of our investigation was to evaluate the dyspnea as a disabling symptom in COPD patients with cardiovascular comorbidity (CVC) especially heart failure. The main aim of this study is to evaluate its intensity in patients with COPD in stages II according GOLD. As in COPD patients, dyspnea is a cardinal symptom which leads to impaired exercise tolerance and the impaired health related quality of life, worsens the prognosis. This is very important for differential diagnosis and treatment of those patients, especially in the early stages of the disease. 


\section{Materials and Methods}

The investigation was conducted from December 2019 to January 2020, on pulmonology and allergology clinic and cardiology clinic of medical faculty in Skopje. We investigated 65 outpatients with COPD, 44 with different type of CVD, Group I, and 21 without CVD, Group II. All patients were with partial chronic respiratory failure (In type 1 respiratory failurehypoxemic). Patients, according GOLD initiative, were in COPD stadium II, $70 \%<$ forced expiratory volume in $1 \mathrm{~s}$ (FEV1)>50\%. Heart condition was diagnosed on the basis of clinical examination, electrocardiography, and echocardiography of the heart. Included patients with CVD were with ejection fraction (EF) $<65 \%$.

Dyspnea was measured with modified MRC (mMRC) dyspnea scale. (mMRC Dyspnoea Scale: 0 "I only get breathless with strenuous exercise," 1 "I get short of breath when hurrying on the level or walking up a slight hill," 2 "I walk slower than people of the same age on the level because of breathlessness or have to stop for breath when walking at my own pace on the level," 3 "I stop for breath after walking about 100 yards or after a few minutes on the level," and 4 "I am too breathless to leave the house" or "I am breathless when dressing") [10].

Patients were examined at one visit (crosssectional study), they were previously diagnosed with both respiratory and CVD. On the visit day, the patients had a history and a clinical examination, post-bronchodilatatory spirometry was performed, body pletismography, Transfer Factor of the Lung for Carbon Monoxide (TLCO), electrocardiography and echocardiography. Then patients answered the questions of mMRC dyspnea scale and COPD assesment test (CAT).

\section{Statistical analysis}

The Chi-squared test and Student's t-test were used to examine the differences in characteristics between patients without HD (no HD) and patients with $\mathrm{HD}$ at baseline (HD). Statistically significant values were taken at $p<0.05$.

\section{Results}

The cohort of 65 COPD outpatients included in investigation was divided in two groups, 44 patients with CVC Group I and 21 without CVC Group II.

Characteristics of COPD patients in Group I and Group II, according demography, spirometry, gas analysis, EF, smoking status, family status, and activity are shown in Table 1.
Table 1: Characteristics of patients according to demography, spirometry, gas analysis, EF (ejection fraction), smoking status, family status, activity

\begin{tabular}{|c|c|c|c|}
\hline Subjects & 44 (with CVD) & 21 (without CVD) & $P$ \\
\hline Age (years) & $65.1 \pm 4.7$ & $64.9 \pm 11.5$ & 0.5 \\
\hline $\mathrm{BMI} \mathrm{m}^{2} / \mathrm{kg}$ & $23.1 \pm 4.1$ & $22 \pm 3.7$ & $<0.05$ \\
\hline FVC (\%) & $81.9 \pm 5.7$ & $84.1 \pm 10.1$ & $<0.001$ \\
\hline FEV1 (\%) & $51.8 \pm 13.2$ & $52.9 \pm 1.5$ & $<0.05$ \\
\hline FEV1/FVC (\%) & $61.9 \pm 12.2$ & $62.8 \pm 9.1$ & $<0.05$ \\
\hline $\mathrm{PaO}_{2} \mathrm{kPa}$ & $8.91 \pm 1.44$ & $8.97 \pm 0.91$ & 0.7 \\
\hline $\mathrm{PaCO}_{2} \mathrm{kPa}$ & $5.4 \pm 0.67$ & $5.9 \pm 0.79$ & 0.1 \\
\hline $\mathrm{EF}\left(\%^{2}\right)$ & $48 \pm 9.5$ & $67 \pm 1.2$ & $<0.001$ \\
\hline Pack years of smoking & $53.1 \pm 1.5$ & $51.4 \pm 1.2$ & $<0.05$ \\
\hline Number of smoking years & $52.3 \pm 2.34$ & $48 \pm 4.4$ & $<0.001$ \\
\hline Number of the present smokers & 38 & 11 & $<0.05$ \\
\hline Impaired activity (\%) & $32 \pm 2.2$ & $23 \pm 3.1$ & $<0.001$ \\
\hline Living with partner of family (\%) & 69 & 71 & 0.1 \\
\hline
\end{tabular}

Patients in both groups were with similar age $(p=0.5)$, BMI was lower in a group without CVC Group II, $(<0.05)$. Hence, in these two groups of COPD patients (GOLD II stage), age and body mass index did not influence on the patients dyspnea scores in this case.

The forced vital capacity and FEV1 were statically significantly higher in Group II.

The level of $\mathrm{PaO}_{2}$ and $\mathrm{PaCO}_{2}$ was not statistically significantly different between the groups.

EF was lower in Group I with CVC (48 \pm 9.5 vs. $67 \pm 1.2, p<0.001$ ), the number of pack years was statistically higher in Group I, also the number of smoking years was higher in Group I, and the number of the present smokers is higher in Group I.

COPD patients in Group I were with statistically significantly higher impaired activity $(p<0.05)$.

Almost equal number of patient of both groups $(p=0.1)$ is living with partner or with family which is a common case in our country and is very good for these patients, and there quality of life, first of all about their emotional and social status, and also patients with good social support have better therapeutic compliance.

Characteristics of COPD patients with (Group I) and without (Group II) CVC according body plethysmography and diffusing capacity of CO (TLCO) are shown in Table 2.

Table 2: Characteristics of patients according to bodypletismography and diffusing capacity of $\mathrm{CO}$

\begin{tabular}{llll}
\hline Subjects & 44 (with CVD) & 20 (without CVD) & $\mathrm{p}$ \\
\hline TLC (L) & $6.7 \pm 2.26$ & $6.4 \pm 1.4$ & 0.1 \\
RV (L) & $2.97 \pm 1.4$ & $2.42 \pm 1.9$ & 0.1 \\
RV/TLC (\%) & $0.46 \pm 0.13$ & $0.42 \pm 2.0$ & 0.1 \\
TLCO (\%) & $57.3 \pm 12.6$ & $58.9 \pm 12.4$ & 0.1 \\
KCO (\%) & $68.7 \pm 18.9$ & $69 \pm 14.8$ & 0.1 \\
\hline TLC: Total lung capacity, RV: Residual volume, CVD: Cardiovascular diseases.
\end{tabular}

The results of patients according body plethysmography and diffusing capacity of $\mathrm{CO}$ showed that the values of TLC, residual volume (RV), RV/TLC, and TLCO are not statistically significantly different also KCO was not statistically significantly different in both groups.

Characteristics of COPD patients with and without CVC, according symptom score measured with CAT, dyspnea measured with mMRC dyspnea score, 
number of exacerbations and hospitalizations are shown in Table 3.

Table 3: Characteristics of patients according to symptom score measured with COPD assesment test (CAT), dyspnea measured with mMRC dyspnea score, number of exacerbations and hospitalizations

\begin{tabular}{llll}
\hline Subjects & 44 (with CVD) & 20 (without CVD) & $\mathrm{p}$ \\
\hline CAT-score & $19.8 \pm 9.1$ & $9.8 \pm 9.1$ & $<0.001$ \\
mMRC dyspnea score & $2.9 \pm 1.4$ & $1.7 \pm 1.4$ & $<0.001$ \\
Exacerbations & $3.0 \pm 1.1$ & $1.0 \pm 2.1$ & $<0.001$ \\
Hospitalizations & $1.0 \pm 1.1$ & $0.3 \pm 2.1$ & $<0.001$ \\
\hline CVD: Cardiovascular diseases, CAT: COPD assessment test, mMRC: Modified medical research council
\end{tabular}

The results of symptom score measured with CAT, dyspnea measured with mMRC dyspnea score, number of exacerbations and hospitalizations in both groups showed statistically significant difference in symptoms between Group I and II in symptom score $(<0.001)$ with the higher values in Group I.

Dyspnea measured with mMRC dyspnea scale showed statistically significantly higher values in Group I (2.9 \pm 1.4$)$ versus Group II $(1.7 \pm 1.4)$, $(p<0.05)$.

The number of exacerbations in Group I $(3.0 \pm 1.1)$ versus Group II was $(1.0 \pm 2.1)$, $(p<001)$, and what is more important the number of severe exacerbation leading to hospitalizations is statistically higher in patients of Group I with CVC versus Group II without CVC $(1.0 \pm 1.1$ vs. $0.3 \pm 2.1),(<0.001)$. Hence, a perception of higher dyspnea in Group I was associated with increased disease severity and a higher morbidity. The higher number of exacerbations especially severe in COPD patients might be associated with the higher mortality.

Patients with COPD who have CVC have an increased risk of high symptoms, which means poor quality of life, increased morbidity, or increased mortality.

\section{Discussion}

COPD is a complex, heterogeneous, and multicomponent disorder, and disease severity can be further exacerbated by the presence of coexisting comorbidities [12]. An analysis of data from 20,296 patients with COPD showed that patients at GOLD stages 3 and 4 were more likely to have 1-3 comorbidities compared with patients with normal lung function (GOLD stage 0) [13], [14]. There is increasing evidence that chronic inflammation (favoring arteriosclerosis) is a key factor in COPD and that inflammation might be the common pathway linking these comorbidities and explaining why they typically develop together [15]. Left heart failure is diagnosed 1-time in one out of five COPD patients after extensive cardiovascular work-up. These frequent coincidences are not only associated with diagnostic difficulties, but also with worse prognosis (5-year survival $31 \%$ vs. $71 \%$ ) [16]. Smoking as the leading risk factor for developing inflammation in COPD, and it is also one of the risk factors of developing CVD, so there are often differential diagnostic challenges [16], [17].

The results of study published in 2018 suggest that HD contributes to the lower health status and higher symptom burden in COPD but does not accelerate the worsening over time [18].

Between COPD and CHD, there is a fairly strong epidemiological relationship, which persists regardless of statistical adjustment for the common risk factors (smoking index, cholesterol level, etc.). Both diseases are characterized by systemic inflammation, oxidative stress, and coagulopathy [11].

Dyspnea is a cardinal symptom of COPD, and its severity and magnitude increase as the disease progresses, leading to significant disability and a negative effect on quality of life. Refractory dyspnea is a common and difficult symptom to treat in patients with advanced COPD. There are many questions concerning optimal management and, specifically, whether various therapies are effective in this setting [19], [20].

Dyspnea is especially pronounced when CVC is present as comorbidity in COPD patients, because the lung and the heart are functionally extremely connected. We expected patients with COPD who have CVC, to have dyspnea even in the early stages and is more pronounced than without CVC, as it is shown by the results of our research.

Some studies have shown that COPD patients are first diagnosed in cardiologic intensive care units with cardiovascular comorbidities (CVC). CVC is one of the most important risk factors of morbidity and mortality of COPD patients. Some studies have shown that COPD patients with cardiovascular comorbidities (CVC) are first diagnosed in cardiologic departments, after some cardiologic events [21], [22].

In our cross-sectional study with aim to evaluate the dyspnea in two groups, COPD patients with CVD (Group I) and without CVD (Group II), we found that the symptoms and especially dyspnea are statistically higher in patients with CVS.

Previously, it was shown that about $40 \%$ of patients with mild and moderate COPD died due to CVC, which is 8-10 times more likely than deaths in the same group due to respiratory insufficiency. During the 5 years of follow-up, COPD patients had a higher rate of hospitalization and death, the cause of which was CHD, stroke, and CHF [19], [23].

Data from large clinical trials such as TORCH and UPLIFT have shown that comorbidities such as CVD and lung cancer are common contributors to mortality among patients with COPD [24], [25].

COPD is regarded as one of the leading causes of morbidity and mortality across the world, yet its proper diagnosis remains a challenge. 
Community-based population studies conducted in North and South America, Europe, Australia, and Asia have revealed that $10-12 \%$ of adults aged 40 years or older have evidence of persistent airflow limitation on spirometry, but only $20-30 \%$ of these subjects have been diagnosed with COPD. These studies collectively suggest that approximately $70 \%$ of COPD worldwide may be underdiagnosed [26].

Conversely, other studies have shown that between $30 \%$ and $60 \%$ of patients with a previous physician diagnosis of COPD do not actually have the disease, and hence they have been overdiagnosed [26].

In our opinion this is especially important in the early stages of the disease, to make an accurate diagnosis, to start early therapy and especially to eliminate risk factors such as smoking.

In the other study, the risk of hospitalization was higher in COPD case patients than in control subjects for all CVD hospitalization and mortality end points. The relative risk (RR) for hospitalization for the composite measure of all study end points was 2.09 (95\% confidence interval [Cl], 1.99-2.20) after adjustment for gender, preexisting CVD study end points, hypertension, hyperlipidemia, and diabetes, and ranged from 1.33 (stroke) to 3.75 (CHF). The adjusted RR for mortality for the composite measure of all study end points was $1.68(95 \% \mathrm{Cl}, 1.50$ to 1.88$)$, ranging from 1.25 (stroke) to $3.53(\mathrm{CHF})$. Younger patients (age $<65$ years) and female patients had a higher risks than older and male participants [27], [28].

COPD was a predictor of CVD hospitalization and mortality over an average follow-up time of nearly 3 years. The finding of a stronger relationship of COPD to CVD outcomes in patients $<65$ years of age suggests that CVD risk should be monitored and treated with particular care in younger adults with COPD [21].

In our investigation, we saw that patients with CVC had more frequent exacerbations and hospitalizations.

\section{Conclusion}

A large number of patients with COPD and also with $\mathrm{CV}$ diseases is undiagnosed and untreated, implying an increased risk for an unfavorable prognosis of both diseases. It follows that anyone diagnosed with significant dyspnea should be screened for the diagnosis or exclusion of COPD, and vice versa for CVD, especially in the early stages, which is very important for the inclusion of preventive measures, especially smoking cessation, and early treatment for both pulmonary and CVD.

\section{References}

1. Gold Initiative for Chronic Obstructive Lung Disease. Global Strategy for Diagnosis, Management, and Prevention of COPD; 2019. Available from: http://www.goldcopdorg/guidelines-globalstrategy-for-diagnosis-management html.2020 [Last accessed: 2021 May 25].

2. van Remoortel $H$, Hornikx M, Langer D, Burtin C, Everaerts $S$, Verhamme $\mathrm{P}$, et al. Risk factors and comorbidities in the preclinical stages of chronic obstructive pulmonary disease. Am J Respir Crit Care Med. 2013;189(1):30-8. https://doi.org/10.1164/ rccm.201307-12400C

PMid:24219412

3. Aisanov Z, Khaltaev N. Management of Cardiovascular Comorbidities in Chronic Obstructive Pulmonary Disease Patients. WHO Global Coordination Mechanism for NCD Prevention and Control. Vol. 12. Geneva, Switzerland: World Health Organization; 2020.

4. Barnes PJ, Celli BR. Systemic manifestations and comorbidities of COPD. Eur Respir J. 2009;33(5):1165-85. https://doi. org/10.1183/09031936.00128008

PMid:19407051

5. Vonk Noordegraaf A, Marcus JT, Roseboom B, Postmus PE, Faes TJ, de Vries PM. The effect of right ventricular hypertrophy on left ventricular ejection fraction in pulmonary emphysema. Chest 1997;112:640-5. https://doi.org/10.1378/chest.112.3.640 PMid:9315795

6. O'Donnell DE, Laveneziana P. Dyspnea and activity limitation in COPD: Mechanical factors. COPD. 2007;4(3):225-36. https:// doi.org/10.1080/15412550701480455 PMid:17729066

7. Müllerová H, Lu C, Li H, Tabberer M. Prevalence and burden of breathlessness in patients with chronic obstructive pulmonary disease managed in primary care. PLoS One. 2014;9(1):e85540. https://doi.org/10.1371/journal.pone.0085540

PMid:24427316

8. Berliner D, Schneider N, Welte T, Bauersachs J. The differential diagnosis of dyspnea. Dtsch Arztebl Int. 2016;113(49):834-45 https://doi.org/10.3238/arztebl.2016.0834

PMid:28098068

9. Cherian M, Jensen D, Tan WC, Mursleen S, Goodall EC Nadeau GA, et al. Dyspnoea and symptom burden in mildmoderate COPD: The Canadian cohort obstructive lung disease study. ERJ Open Res. 2021;7(2):00960-2020. https://doi. org/10.1183/23120541.00960-2020 PMid:33898621

10. Bestall JC, Paul EA, Garrod R, Garnham R, Jones PW, Wedzicha JA. Usefulness of the medical research council (MRC) dyspnoea scale as a measure of disability in patients with chronic obstructive pulmonary disease. Thorax. 1999;54(7):581-6. https://doi.org/10.1136/thx.54.7.581 PMid: 10377201

11. Giezeman $M$, Hasselgren $M$, Lisspers $K$, Ställberg $B$, Montgomery S, Janson C, et al. Influence of comorbid heart disease on dyspnea and health status in patients with COPD-a cohort study. J Chron Obstruct Pulmon Dis. 2018;13:3857-65. https://doi.org/10.2147/COPD.S175641 PMid:30568437

12. Janson C, Marks G, Buist S, Gnatiuc L, Gislason T, McBurnie MA, et al. The impact of COPD on health status: Findings from the BOLD study. Eur Respir J. 2013;42(6):1472-83 https://doi. org/10.1183/09031936.00153712

PMid:23722617

13. Parshall MB, Schwartzstein RM, Adams L, Banzett RB, 
Manning $\mathrm{HL}$, Bourbeau J, i. An official American thoracic society statement: Update on the mechanisms, assessment, and management of dyspnea. Am J Respir Crit Care Med. 2012;185(4):435-52. https://doi.org/10.1164/ rccm.201111-2042ST

PMid:22336677

14. Ni H, Moe S, Soe Z, Myint KT, Viswanathan KN. Combined aclidinium bromide and long-acting beta2-agonist for chronic obstructive pulmonary disease (COPD). Cochrane Database Syst Rev. 2018;12(12):CD011594. https://doi. org/10.1002/14651858.CD011594.pub2

PMid:305365667

15. Hajiro T, Nishimura K, Tsukino M, Ikeda A, Oga T. Stages of disease severity and factors that affect the health status of patients with chronic obstructive pulmonary disease. Respir Med. 2000;94(9):841-6. https://doi.org/10.1053/rmed.2000.0804 PMid: 11001074

16. Diab N, Gershon AS, Sin DD, Tan WC, Bourbeau J, Boulet LP, et al. Underdiagnosis and overdiagnosis of chronic obstructive pulmonary disease.Am JRespirCritCareMed 2018;198(9):1130-9. https://doi.org/10.1164/rccm.201804-0621Cl PMid:29979608

17. Price D, Freeman D, Cleland J, Kaplan A, Cerasoli F. Earlier diagnosis and earlier treatment of COPD in primary care. Prim Care Respir J. 2011;20:15-22. https://doi.org/10.4104/pcrj.2010.00060 PMid:20871945

18. Rusinaru D, Saaidi I, Godard S, Mahjoub H, Battle C Tribouilloy C. Impact of chronic obstructive pulmonary disease on long-term outcome of patients hospitalized for heart failure. Am J Cardiol. 2008;101(3):353-8. https://doi.org/10.1016/j. amjcard.2007.08.046

PMid:18237599

19. O'Donnell DE, Milne KM, James MD, de Torres JP, Neder JA. Dyspnea in COPD: New mechanistic insights and management implications. Adv Ther. 2020;37(1):41-60. https://doi. org/10.1007/s12325-019-01128-9 PMid:31673990

20. Cooper CB. The connection between chronic obstructive pulmonary disease symptoms and hyperinflation and its impact on exercise and function. Am J Med. 2006;119(10):21-31. https://doi.org/10.1016/j.amjmed.2006.08.004

PMid:16996896
21. Antoniu SA. Descriptors of dyspnea in obstructive lung diseases. Multidiscip Respir Med. 2010;5(3):216-9. https://doi. org/10.1186/2049-6958-5-3-216

PMid:22958466

22. Vicent L, Olarte JM, Puente-Maestu L. Degree of dyspnoea at admission and discharge in patients with heart failure and respiratory diseases. BMC Palliat Car. 2017;16(1):35. https:// doi.org/10.1186/s12904-017-0208-x

PMid:28532487

23. Trinkmann F, Saur J, Borggrefe M, Akin I. Cardiovascular comorbidities in chronic obstructive pulmonary disease (COPD)-current considerations for clinical practice. J Clin Med. 2019;8(1):69. https://doi.org/10.3390/jcm8010069 PMid:30634565

24. Decramer M, Celli B, Kesten S, Lystig T, Mehra S, Tashkin DP. Effect of tiotropium on outcomes in patients with moderate chronic obstructive pulmonary disease (UPLIFT): A prespecified subgroup analysis of a randomised controlled trial. UPLIFT investigators. Lancet. 2009;374(9696):1171-8. https://doi. org/10.1016/S0140-6736(09)61298-8

PMid:19716598

25. Calverley PM, Anderson JA, Celli B, Ferguson GT, Jenkins C, Jones PW, et al, TORCH Investigators. Salmeterol and fluticasone propionate and survival in chronic obstructive pulmonary disease. N Engl J Med. 2007;356(8):775-89. https:// doi.org/10.1056/NEJMoa063070

PMid: 17314337

26. Hawkins NM, Petrie MC, Jhund PS, Chalmers GW, Dunn FG, McMurray $\mathrm{JJ}$, et al. Heart failure and chronic obstructive pulmonary disease: Diagnostic pitfalls and epidemiology. Eur J Heart Fail. 2009;11(2):130-9. https://doi.org/10.1093/eurjhf/ hfn013

PMid: 19168510

27. Huiart L, Ernst P, Suissa S. Cardiovascular morbidity and mortality in COPD. Chest. 2005;128(4):2640-6. https://doi. org/10.1378/chest.128.4.2640 PMid:16236937

28. Sidney S, Sorel M, Quesenberry CP Jr., DeLuise C, Lanes S, Eisner MD. COPD and incident cardiovascular disease hospitalizations and mortality: Kaiser Permanente Medical Care Program. Chest. 2005;128(4):2068-75. https://doi.org/10.1378/chest.128.4.2068 PMid:16236856 